\title{
TIME-VARYING RISK AVERSION AND THE PROFITABILITY OF MOMENTUM TRADES
}

\section{RIZA DEMIRER 1* AND SHRIKANT P. JATEGAONKAR²}

1. Department of Economics \& Finance, Southern Illinois University Edwardsville, Edwardsville, IL 62026- 1102, USA.

2. Department of Economics \& Finance, Southern Illinois University Edwardsville, Edwardsville, IL 62026- 1102, USA.

* Corresponding Author: Riza Demirer. Department of Economics \& Finance, Southern Illinois University Edwardsville, Edwardsville, IL 62026- 1102, USA. 㿿 +00 (1) 6186502939

$\triangle$ rdemire@sive.edu

\begin{abstract}
We show that time-varying risk aversion serves as a significant predictor of stock market momentum in the U.S. and globally. Risk aversion is found to be a robust predictor of momentum returns even after controlling for various well-established stock market predictors and absorbs the predictive power of market volatility. Finally, we show that conditioning momentum trades based on the risk aversion state can help improve the risk/return profile of the conventional momentum strategy.
\end{abstract}

Keywords: Momentum, Risk aversion, Anomalies

JEL: C20, G10

\section{Introduction}

Pioneered by the works of Jegadeesh and Titman (1993) and Asness (1994), the momentum effect in stock returns has remained a puzzle in the academic literature without a definitive explanation for why this well-studied anomaly persists in stock returns, both in the U.S. and globally. The attempts to explain this anomaly include (i) Daniel et al. (1998), Hong and Stein (1999) based on overconfidence and underreaction to information; (ii) Nofsinger and Sias (1999), Demirer and Zhang (2019a) based on herding behaviour among investors; (iii) Hong et al. (2000) via gradual information diffusion; (iv) Hvidkjaer (2006) and Sadka (2006) based on how small traders and noise traders react to information; in addition to the risk-based explanations in Jegadeesh and Titman (2001), Avramov and Chordia (2006) and Liu and Zhang (2008), among others. A growing strand of the asset pricing literature, however, establishes a link between investor sentiment and market anomalies like size, value and momentum (e.g. Baker and Wurgler, 2006; Frazzini and Lamont, 2008 and Antoniou et al., 2013). Given that investor sentiment is closely related to risk aversion (e.g. Bams, et al., 2017) and the evidence that links investor sentiment to herding and speculative behaviour in financial markets (e.g. Lemmon and Ni, 2011; Blasco et al., 2012), this paper utilizes the recently developed measure of time-varying risk aversion by Bekaert et al. (2017) and examines (i) the role of time-varying risk aversion as a predictor of momentum returns; and (ii) whether or not the predictive power of risk aversion can be exploited as part of an investment strategy to enhance the profitability of the conventional momentum strategy.

The literature has offered several explanations to link sentiment to momentum and reversals in returns, although largely from a behavioural perspective. Earlier studies including Nofsinger 
and Sias (1999) and Sias (2004) show that asset returns follow the herd, while other studies including Dasgupta et al. (2011), Singh (2013), and Brown et al. (2014) document return reversals as a result of herding. The rationale is that herding drives correlated trading behaviour among investors, thus reinforcing trades by informed traders based on past performance, mimicked by noise (sentiment) traders. Considering that sentiment is a driver of herding tendencies among investors (e.g. Chiang and Lin, 2019) and that sentiment is closely related to risk aversion (e.g. Bams, et al., 2017), one possible channel that links time-varying risk aversion to momentum is therefore herd formation among investors, driven by sentiment spillovers across investors. This argument is indeed supported by a number of studies including Brown and Cliff (2005) and Baker and Wurgler (2006) relating sentiment to the comovement in the demand shocks of noise traders, which in turn, results in persistent mispricing. Baker and Wurgler (2007) further argue that subsequent market correction results in the predictability of contrarian patterns as sentiment dissipates in the long run. Accordingly, the literature offers ample arguments that link changes in risk preferences (via sentiment) to momentum and reversals in financial markets.

Another line of research proposes the gradual diffusion of information across the more and less informed traders as a driver of momentum (e.g. Hong and Stein, 1999). The underlying idea is that underreaction to news that is not fully arbitraged away by momentum traders, who condition their trades on past prices and not on all public information, eventually leads to momentum cycles with short-term profits and long-term losses for those traders. Building on this argument, Antoniou et al. (2013) argue that sentiment can drive momentum by affecting the pricing of past winners and losers asymmetrically due to a combination of cognitive dissonance that slows the diffusion of information and short-selling constraints that impede arbitrage forces to operate, which in turn, results in asymmetries in how information is priced out for the past winner and loser stocks. Arguing that optimistic sentiment will slow the diffusion of bad news for loser stocks (and vice versa for good news for winner stocks when sentiment is low). Antoniou et al. (2013) show that momentum will be stronger during high sentiment (optimistic) periods due to more severe arbitrage constraints as arbitrage would involve costly short selling of loser stocks during optimistic states.

In the case of the emerging literature on risk aversion, a number of recent studies establish a close link between time-varying risk aversion and a global financial cycle that drives capital flows and stock market valuations (e.g. Miranda-Agrippino and Rey, 2015; Rey, 2018). Xu (2017) and Demirer et al. (2018) further show that risk aversion serves as a significant driver of return comovement across global stock markets. Clearly, from an economic perspective, one can establish a close link between changes in investors' risk appetite and their tendency to be involved in risky trades such as momentum trading. This argument is indeed supported by the evidence that links investor sentiment to herding and speculative behaviour in financial markets (e.g. Lemmon and Ni, 2011; Blasco et al., 2012). Furthermore, given the recent evidence in Demirer and Zhang (2019b) that investor herding significantly contributes to stock market momentum, particularly via its effect on how past loser stocks perform in subsequent periods, one can argue that the market's state with regards to the level of risk aversion can explain (perhaps predict) the profitability of momentum trades as investors' tendency to herd would be closely linked to changes in risk attitudes.

Clearly, as Guiso et al. (2018) note, risk aversion can fluctuate due to changes in wealth, background risk, and emotions that alter risk appetite. To address this distinction, Bekaert et al. (2017) derive a formulation for time-varying risk aversion based on a utility function in the hyperbolic absolute risk aversion (HARA) class. As the authors note, this measure of risk aversion that we utilize in our tests distinguishes the time variation in economic uncertainty (i.e. the amount of risk) from the time variation in changes in risk preferences (i.e. the price of risk). To that end, the availability of the measure of time-varying risk aversion presents an 
interesting opening, allowing us to examine the role of risk aversion as a determinant of momentum returns independently from the effect's economic uncertainty.

Examining monthly momentum returns for the U.S. and global stock markets, our findings suggest that time-varying risk aversion indeed plays a primary role in the subsequent performance of momentum trades. While positive market states contribute to the profitability of momentum trades, we also find that momentum payoffs are significantly greater during periods of low-risk aversion, consistently both in the U.S. and globally. Further analysis shows that time-varying risk aversion absorbs the predictive power of market volatility as a predictor and is robust to the inclusion of various well-established stock market predictors in our models. Finally, we show that the predictive power of risk aversion over momentum returns can be exploited in a conditional momentum strategy based on the level of risk aversion. We observe that the conditional momentum strategy offers a more favourable risk-adjusted return (implied by the information ratio) compared to the conventional momentum strategy, suggesting that conditioning momentum trades based on the risk aversion state can help improve the risk/return profile of the conventional momentum strategy. The remainder of the paper is organized as follows. Section 2 discusses the data and methodology. Section 3 presents the empirical results and Section 4 concludes.

\section{Data and Methodology}

We utilize monthly Fama-French U.S. and global (ex U.S.) momentum returns over January 1991 through December 2016, obtained from Kenneth French's data library.' The time-varying riskaversion series, originally developed by Bekaert et al. (2017), is obtained from Nancy Xu's website. ${ }^{2}$ Based on a set of six financial instruments including term spread, credit spread, a detrended dividend yield, realized and risk-neutral equity return variance and realized corporate bond return variance, this recently proposed measure of risk-aversion distinguishes the time variation in economic uncertainty (the amount of risk) from time variation in risk aversion (the price of risk), thus provides an unbiased representation of dynamic changes in the risk preferences of investors in financial markets. Our sample period is governed by the availability of the risk aversion data. As will be discussed later, we also use several control variables in our predictive regressions, based on the well-cited study of Goyal and Welch (2008). ${ }^{3}$

We first examine mean Fama-French U.S. (USmom) and global momentum (Gmom) returns during high vs low-risk aversion states. We define a month to be in high (low) risk aversion state if the lagged 3-month risk aversion is greater (smaller) than the lagged 12-month risk aversion. ${ }^{4}$ In addition, following Wang and $X \cup(2015)$, we define a month to be in a positive (negative) market state if the lagged 36-month market return is positive (negative). ${ }^{5}$ We then perform a two-way sort based on market and risk aversion states, allowing us to see if momentum payoffs vary with risk aversion state after controlling for the market state. Next, we run various predictive regressions in the form

$$
\operatorname{mom}_{t}=a+b \cdot X_{t-1}+\varepsilon_{t}
$$

\footnotetext{
1 Data publicly available at http://mba.tuck.dartmouth.edu/pages/faculty/ken.french/data library.html.

2 We thank Nancy Xu for providing the data on risk aversion https://www.nancyxu.net/risk-aversion-index.

${ }^{3}$ Data on predictor variables are available on Amit Goyal's website at http://www.hec.unil.ch/agoyal/.

${ }^{4}$ Robustness checks with alternative lags for the risk aversion index to determine the risk aversion state yield similar results and are available upon request.

${ }^{5}$ Note that we have two different proxies for markets returns, U.S and global market returns obtained from Ken French's website, to examine U.S. and global momentum, respectively.
} 
where mom is the U.S. (global) momentum return in month $t$, and $X_{t-1}$ is the set of predictor variables. The predictors include MKT (lagged 36-month return), VOL (lagged 12-month market volatility), default spread, term spread, Treasury yield, and dividend yield for month $t-1$. Finally, risk aversion is the lagged 3-month risk aversion index to be consistent with our earlier definition of high/low-risk aversion states. ${ }^{6}$

\section{Empirical Results}

Table 1 presents the mean momentum payoffs obtained from two-way sorts. We observe in Panel A that both U.S. and global momentum payoffs are significantly higher during periods of low-risk aversion. For example, mean U.S. momentum payoffs are $0.917 \%$ and $-0.259 \%$ during low and high-risk aversion periods, respectively. Comparing the results in Panels B and C, consistent with Wang and $\mathrm{XU}$ (2015), higher momentum payoffs are found during positive market states. However, when we further sort the samples based on the level of risk aversion, we see that low-risk aversion is the primary determinant of momentum profitability, particularly for the U.S.

\section{Table 1: Momentum during high and low-risk aversion states}

\begin{tabular}{|c|c|c|c|c|c|c|}
\hline & \multicolumn{3}{|c|}{ U.S. Momentum } & \multicolumn{3}{|c|}{ Global Momentum (ex U.S.) } \\
\hline \multicolumn{7}{|c|}{ Panel A: Mean returns conditional on the level of risk aversion } \\
\hline & Overall & High R.A. & Low RA & Overall & High R.A. & Low R.A. \\
\hline Mean & $0.476^{*}$ & -0.259 & $0.917^{* * *}$ & $0.708^{* * *}$ & 0.443 & $0.866^{* * *}$ \\
\hline t-stat & $(1.720)$ & $(-0.460)$ & (3.210) & (3.450) & $(1.150)$ & (3.700) \\
\hline $\mathbf{N}$ & 312 & 117 & 195 & 312 & 117 & 195 \\
\hline \multicolumn{7}{|c|}{ Panel B: Mean returns during POSITIVE market states, conditional on the level of risk aversion. } \\
\hline & Overall & High R.A. & Low RA & Overall & High R.A. & Low R.A. \\
\hline Mean & $0.771^{* * *}$ & 0.284 & $1.065^{* * *}$ & $0.956^{* * *}$ & $0.906^{* * *}$ & $0.988^{* * *}$ \\
\hline t-stat & $(2.950)$ & $(0.600)$ & $(3.470)$ & $(4.440)$ & $(2.920)$ & (3.370) \\
\hline $\mathbf{N}$ & 263 & 99 & 164 & 229 & 89 & 140 \\
\hline \multicolumn{7}{|c|}{ Panel C: Mean returns during NEGATIVE market states, conditional on the level of risk aversion. } \\
\hline & Overall & High R.A. & Low RA & Overall & High R.A. & Low R.A. \\
\hline Mean & -1.108 & -3.249 & 0.136 & 0.022 & -1.029 & 0.557 \\
\hline t-stat & $(-1.050)$ & $(-1.290)$ & $(0.180)$ & $(0.050)$ & $(-0.830)$ & $(1.540)$ \\
\hline $\mathbf{N}$ & 49 & 18 & 31 & 83 & 28 & 55 \\
\hline
\end{tabular}

Note: This table reports the mean U.S. Fama-French (USmom) and global (Gmom) momentum returns for the period January 1991 through December 2016. Panel A reports the mean momentum returns independent of market state, however conditional on high and low-risk aversion. We define a month to be in high (low) risk aversion state if the lagged 3-month average risk aversion is greater (smaller) than the lagged 12-month average risk aversion. Panels B and $C$ report the momentum returns during positive and negative market states, respectively, conditional on high and low-risk aversion. A month is in positive (negative) market state if the lagged 36-month market return is positive (negative). The panel reports the results from two-way sorts for the market state and risk aversion state. The t-stats (in

\footnotetext{
${ }^{6}$ For robustness, we have also tried alternative definitions for risk aversion and found qualitatively similar results. Results are available upon request.
} 
parenthesis) and number of observations ( $\mathrm{N}$ ) are reported for each group. ${ }^{* * * * * *}$, and ${ }^{*}$ indicate statistical significance at $1 \%, 5 \%$, and $10 \%$, respectively.

Interestingly, in Panel C, we observe positive mean momentum payoffs during low-risk aversion months even when the market is in a negative state, providing the initial evidence that risk aversion can indeed be the primary driver of momentum payoffs even after controlling for the state of the market. This evidence is further supported visually in Figures $1 \mathrm{a}$ and $1 \mathrm{~b}$ with positive spikes in lagged risk aversion values associated with major crashes in momentum payoffs in both plots. Likewise, we observe that downward movements in risk aversion values are closely linked to positive spikes in momentum payoffs.

Figure 1a: Monthly U.S. momentum returns and lagged risk aversion.

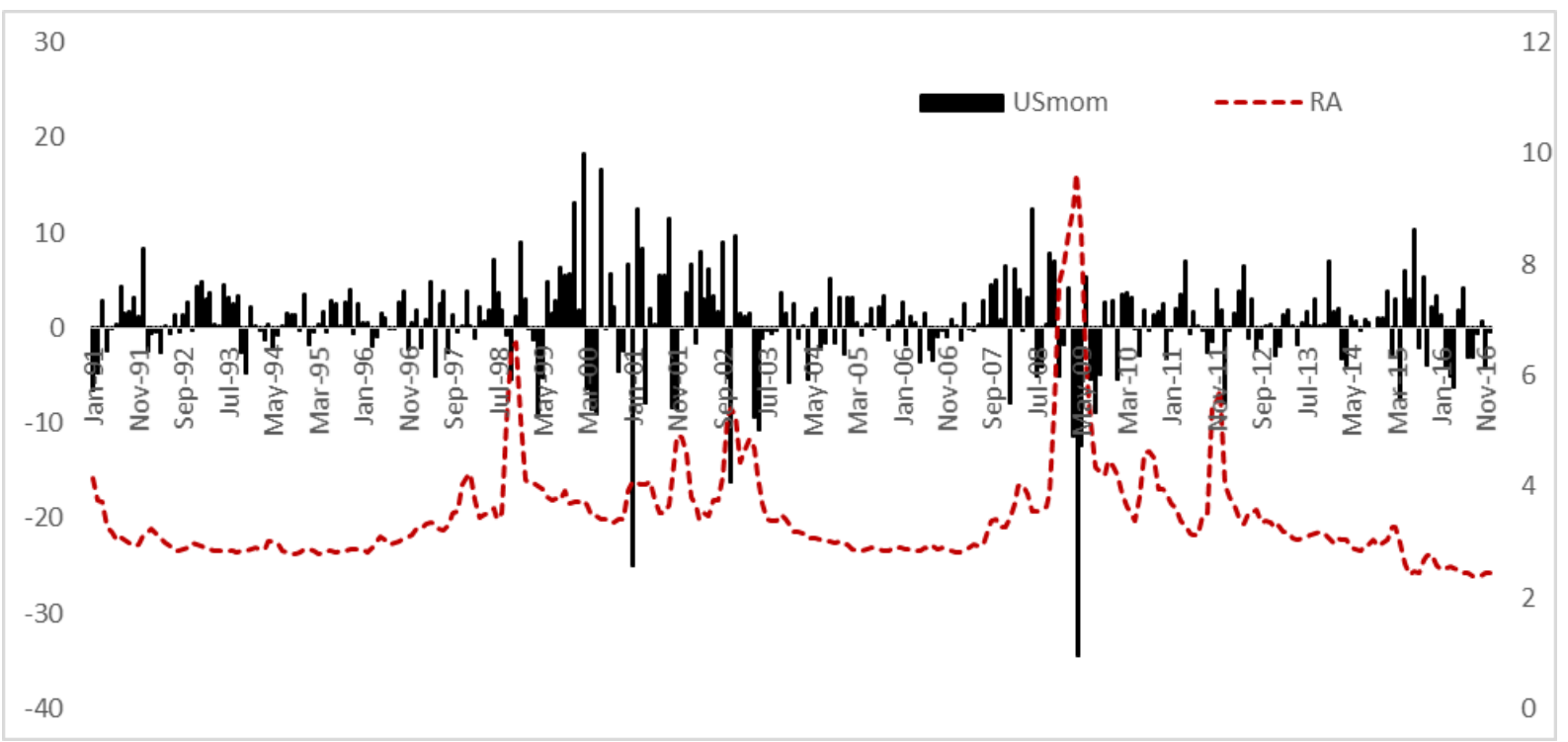

Figure 1b: Monthly global momentum returns and lagged risk aversion

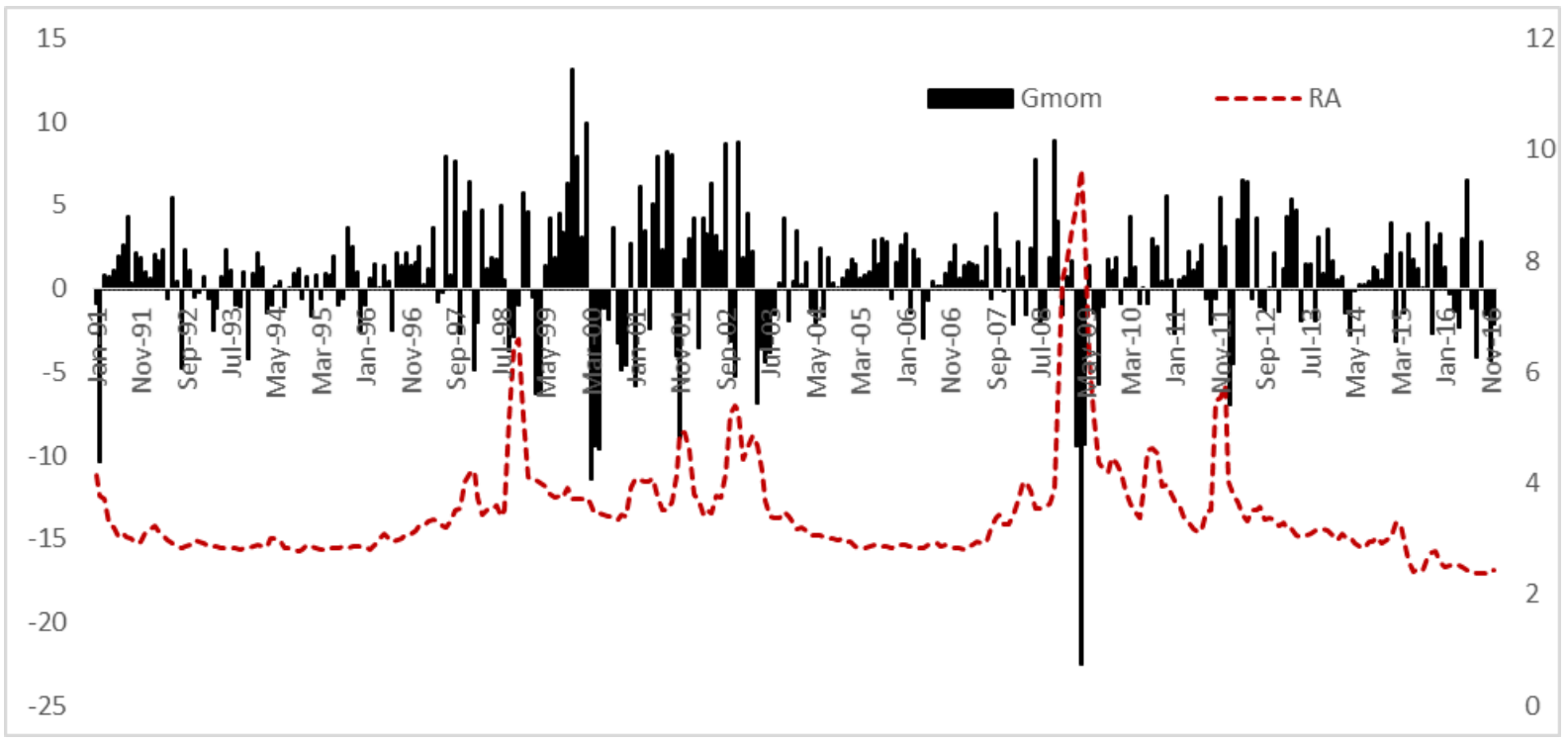

Note: The figures plot monthly U.S. (USmom) and global (Gmom) momentum returns along with lagged risk aversion (R.A.). Risk aversion series is computed as the average risk aversion over months ( $t, t-3)$. 
The formal predictive tests, presented in Table 2, further confirm the predictive power of risk aversion over momentum returns both for the U.S. and global markets. While the market return (MKT) positively predicts momentum returns, consistent with the results in Table 1 (and those documented in Wang and $\mathrm{XU}, 2015)$, we observe that risk aversion is a significant, negative predictor for momentum payoffs. Interestingly, while market volatility (VOL) comes out significant when used in the model alone, it loses its significance when risk aversion is introduced to the model, suggesting that risk aversion absorbs the predictive power of market volatility. Finally, we see that risk aversion remains highly significant even after controlling for various stock market predictors based on Goyal and Welch (2008). Overall, our findings show that risk aversion is a robust predictor of momentum returns, with a high level of risk aversion predicting negative momentum payoffs.

\section{Table 2: Predictive Regressions}

\begin{tabular}{|c|c|c|c|c|c|c|c|c|}
\hline & \multicolumn{5}{|c|}{ U.S. Momentum } & \multicolumn{3}{|c|}{ Global Momentum (ex U.S.) } \\
\hline MKT & $\begin{array}{c}1.179^{* * * *} \\
(3.33)\end{array}$ & & $\begin{array}{l}0.634 \\
(1.65)\end{array}$ & $\begin{array}{c}1.426^{* * *} \\
(2.91)\end{array}$ & $\begin{array}{c}0.637^{* *} \\
(2.19)\end{array}$ & & $\begin{array}{l}-0.019 \\
(-0.05)\end{array}$ & $\begin{array}{l}0.672 \\
(1.53)\end{array}$ \\
\hline VOL & & $\begin{array}{c}-0.445^{* * *} \\
(-2.64)\end{array}$ & $\begin{array}{l}0.236 \\
(1.05)\end{array}$ & $\begin{array}{l}-0.094 \\
(-0.39)\end{array}$ & & $\begin{array}{c}-0.409^{* * *} \\
(-3.06)\end{array}$ & $\begin{array}{l}-0.134 \\
(-0.75)\end{array}$ & $\begin{array}{l}-0.133 \\
(-0.71)\end{array}$ \\
\hline $\begin{array}{l}\text { Risk } \\
\text { Aversion }\end{array}$ & & & $\begin{array}{c}-1.371^{* * *} \\
(-3.66)\end{array}$ & $\begin{array}{c}-1.292^{* * *} \\
(-2.97)\end{array}$ & & & $\begin{array}{c}-0.727^{* * *} \\
(-2.70)\end{array}$ & $\begin{array}{l}-0.738^{* *} \\
(-2.20)\end{array}$ \\
\hline $\begin{array}{l}\text { Default } \\
\text { Spread }\end{array}$ & & & & $\begin{array}{l}1.167 \\
(1.08)\end{array}$ & & & & $\begin{array}{l}0.562 \\
(0.70)\end{array}$ \\
\hline $\begin{array}{l}\text { Term } \\
\text { Spread }\end{array}$ & & & & $\begin{array}{l}0.899^{* *} \\
(3.11)\end{array}$ & & & & $\begin{array}{l}0.637^{* *} \\
(2.57)\end{array}$ \\
\hline $\begin{array}{l}\text { Treasury } \\
\text { Yield }\end{array}$ & & & & $\begin{array}{l}-0.123 \\
(-1.12)\end{array}$ & & & & $\begin{array}{l}-0.001 \\
(-0.01)\end{array}$ \\
\hline Div Yield & & & & $\begin{array}{c}-0.109^{* * *} \\
(-3.75)\end{array}$ & & & & $\begin{array}{c}-0.081^{* * *} \\
(-3.38)\end{array}$ \\
\hline Intercept & $\begin{array}{l}-0.562 \\
(-1.36)\end{array}$ & $\begin{array}{c}2.233^{* * * *} \\
(3.10)\end{array}$ & $\begin{array}{c}3.759^{* * *} \\
(3.04)\end{array}$ & $\begin{array}{c}-17.337^{* * *} \\
(-3.11)\end{array}$ & $\begin{array}{l}0.333 \\
(1.17)\end{array}$ & $\begin{array}{c}2.493^{* * *} \\
(4.05)\end{array}$ & $\begin{array}{c}3.881^{* * * *} \\
(3.63)\end{array}$ & $\begin{array}{c}-12.470^{* * * *} \\
(-2.69)\end{array}$ \\
\hline $\mathbf{N}$ & 312 & 312 & 312 & 312 & 282 & 282 & 282 & 282 \\
\hline Adj. $R^{2}$ & 0.032 & 0.019 & 0.073 & 0.111 & 0.013 & 0.029 & 0.048 & 0.082 \\
\hline
\end{tabular}

Note: The table reports the results of the predictive regressions of U.S. (USmom) and global (Gmom) momentum returns against risk aversion, after controlling for various predictors. MKT is the lagged 36-month stock market return, and VOL is the lagged 12-month stock market volatility. Stock market variables are based on the U.S. (Global) market index when the dependent variable is USmom (Gmom). Risk Aversion (R.A.) is the lagged 3-month average of the risk aversion index. Control predictor variables include lagged values for Default_Spread, Term_Spread, Treasury_Yield, and Div_Yield based on Goyal and Welch (2008). .**, ${ }^{* *}$, and ${ }^{*}$ indicate statistical significance at $1 \%, 5 \%$, and $10 \%$, respectively.

As noted earlier, the literature offers ample evidence that links investor sentiment to stock market momentum and reversals, largely from a behavioural perspective. Therefore, to explore the possible role of sentiment in our predictive models, we utilize two alternative sentiment 
proxies that are well-cited in the literature, namely the sentiment indexes by Baker and Wurgler (2006) and Huang et al. (2015). ${ }^{7}$ Table 3 presents the results.

\section{Table 3: Controlling for Sentiment}

\begin{tabular}{|c|c|c|c|c|c|c|c|c|}
\hline & \multicolumn{4}{|c|}{ U.S. Momentum } & \multicolumn{4}{|c|}{ Global Momentum (ex U.S.) } \\
\hline & M1 & M2 & M3 & M4 & M5 & M6 & M7 & M8 \\
\hline \multirow[t]{2}{*}{ MKT } & & $1.454^{* * *}$ & & $1.408^{* * *}$ & & 0.653 & & 0.672 \\
\hline & & (2.93) & & $(2.86)$ & & $(1.46)$ & & (1.53) \\
\hline \multirow[t]{2}{*}{ VOL } & & -0.107 & & -0.125 & & -0.105 & & -0.144 \\
\hline & & $(-0.43)$ & & $(-0.51)$ & & $(-0.55)$ & & $(-0.76)$ \\
\hline Risk Aversion & & $-1.283^{* * *}$ & & $-1.269^{* * *}$ & & $-0.623^{*}$ & & $-0.686^{*}$ \\
\hline (R.A.) & & $(-2.76)$ & & $(-2.73)$ & & $(-1.74)$ & & $(-1.96)$ \\
\hline \multirow[t]{2}{*}{ PLS } & 0.565 & -0.505 & & & 0.219 & -1.757 & & \\
\hline & (1.32) & $(-0.21)$ & & & $(0.69)$ & $(-0.96)$ & & \\
\hline \multirow[t]{2}{*}{ PLS * R.A. } & & 0.248 & & & & 0.484 & & \\
\hline & & $(0.40)$ & & & & (1.03) & & \\
\hline \multirow[t]{2}{*}{ BWS } & & & $0.937^{* *}$ & -0.362 & & & $0.617^{*}$ & -1.438 \\
\hline & & & $(2.09)$ & $(-0.15)$ & & & $(1.86)$ & $(-0.74)$ \\
\hline \multirow[t]{2}{*}{ BWS * R.A. } & & & & 0.202 & & & & 0.485 \\
\hline & & & & $(0.32)$ & & & & (0.98) \\
\hline \multirow[t]{2}{*}{ Default Spread } & & 1.173 & & 1.49 & & 0.237 & & 0.935 \\
\hline & & $(1.01)$ & & (1.30) & & $(0.27)$ & & $(1.11)$ \\
\hline \multirow[t]{2}{*}{ Term Spread } & & $0.888^{* * *}$ & & $0.927^{* * *}$ & & $0.652^{* * *}$ & & $0.643^{* *}$ \\
\hline & & $(2.98)$ & & $(3.12)$ & & $(2.62)$ & & $(2.49)$ \\
\hline \multirow[t]{2}{*}{ Treasury Yield } & & -0.120 & & -0.111 & & -0.009 & & 0.013 \\
\hline & & $(-1.08)$ & & $(-1.00)$ & & $(-0.10)$ & & $(0.15)$ \\
\hline \multirow[t]{2}{*}{ Div Yield } & & $-0.101^{* * *}$ & & $-0.103^{* * *}$ & & $-0.079^{* * *}$ & & $-0.064^{* *}$ \\
\hline & & $(-3.37)$ & & $(-3.32)$ & & $(-3.16)$ & & $(-2.35)$ \\
\hline \multirow[t]{2}{*}{ Intercept } & $0.554^{*}$ & $-16.034^{* * *}$ & 0.249 & $-16.847^{* * *}$ & $0.738^{* * *}$ & $-12.633^{* *}$ & $0.558^{* *}$ & $-10.181^{* *}$ \\
\hline & $(1.96)$ & $(-2.76)$ & $(0.402)$ & $(-2.90)$ & (3.51) & $(-2.57)$ & $(2.54)$ & $(-2.02)$ \\
\hline $\mathbf{N}$ & 312 & 312 & 312 & 312 & 312 & 282 & 312 & 282 \\
\hline Adj. $R^{2}$ & 0.002 & 0.108 & 0.011 & 0.107 & -0.002 & 0.079 & 0.008 & 0.082 \\
\hline
\end{tabular}

Note: The table reports the results of the predictive regressions of U.S. (USmom) and global (Gmom) momentum returns against risk aversion, after controlling for various predictors. MKT is the lagged 36-month stock market return, and VOL is the lagged 12-month stock market volatility. Stock market variables are based on the U.S. (Global) market index when the dependent variable is USmom (Gmom). Risk Aversion (R.A.) is the lagged 3-month average of the risk aversion index. B\&W Sentiment (BWS) is the investor sentiment of Baker and Wurgler (2006), and PLS is the sentiment index of Huang et al. (2015). Consistent with the construction of R.A., we use the lagged 3-month average of both proxies for investor sentiment. Control predictor variables include lagged values for Default_Spread, Term_Spread, Treasury_Yield, and Div_Yield based on Goyal and Welch (2008). ${ }^{* * * * *}$, and ${ }^{*}$ indicate statistical significance at $1 \%, 5 \%$, and $10 \%$, respectively.

While the PLS sentiment index of Huang et al. (2015) is not significant by itself in Models 1 and 5 , we see in Models 3 and 7 that the sentiment proxy of Baker and Wurgler (2006) indeed has predictive power over momentum returns. However, we also see in Models 2, 4, 6 and 8 that

\footnotetext{
7 We thank an anonymous reviewer for the suggestion to control for sentiment.
} 
risk aversion retains its predictive power even in the presence of sentiment proxies. It must, however, be noted that the sentiment proxies of Baker and Wurgler (2006) and Huang et al. (2015) are, by construction, based on the information contained in the closed-end fund discount rate, share turnover, number of initial public offerings (IPOs), first-day returns of IPOs, dividend premium, and the equity share in new issues. As Huang et al. (2015) note, the predictive power of these sentiment indexes is primarily driven by the cash-flow channel and not the discount rate channel that relates to changes in risk preferences. Given our findings in Table 3, one can argue that risk aversion indeed captures the time variation in discount rates that is driven by the changes in risk preferences.

To provide further insight into the risk aversion-momentum relationship, we present in Table 4, the results of the predictive regressions for winner and loser portfolio returns separately. Winner (loser) portfolios refer to the highest (lowest) decile portfolios sorted on their past returns as computed by Ken French. The findings in Table 4 suggest that the predictive power of risk aversion over momentum profitability largely stems from the predictive information it captures over the performance of past loser stocks.

Table 4: Asymmetric Predictability.

\begin{tabular}{|c|c|c|c|c|}
\hline & \multicolumn{2}{|c|}{ U.S. Momentum } & \multicolumn{2}{|c|}{ Global Momentum (ex U.S.) } \\
\hline & Winner Stocks & Loser Stocks & Winner Stocks & Loser Stocks \\
\hline \multirow[t]{2}{*}{ MKT } & -0.408 & $-1.834^{* * *}$ & -0.335 & -1.016 \\
\hline & $(-0.79)$ & $(-2.77)$ & $(-0.57)$ & $(-1.49)$ \\
\hline \multirow[t]{2}{*}{ VOL } & 0.329 & 0.423 & -0.064 & 0.0678 \\
\hline & $(1.31)$ & (1.32) & $(-0.26)$ & $(0.23)$ \\
\hline \multirow[t]{2}{*}{ Risk Aversion } & $1.113^{* *}$ & $2.405^{* * *}$ & 0.482 & $1.223^{* *}$ \\
\hline & (2.42) & (4.09) & $(1.08)$ & (2.35) \\
\hline \multirow[t]{2}{*}{ Default Spread } & $-4.732^{* * *}$ & $-5.899 * * *$ & -1.201 & -1.763 \\
\hline & $(-4.14)$ & $(-4.04)$ & $(-1.12)$ & $(-1.41)$ \\
\hline \multirow[t]{2}{*}{ Term Spread } & -0.359 & $-1.258^{* * *}$ & -0.029 & $-0.667^{*}$ \\
\hline & $(-1.17)$ & $(-3.22)$ & $(-0.09)$ & $(-1.73)$ \\
\hline \multirow[t]{2}{*}{ Treasury Yield } & -0.079 & 0.044 & 0.023 & 0.023 \\
\hline & $(-0.68)$ & (0.29) & (0.19) & $(0.17)$ \\
\hline \multirow[t]{2}{*}{ Div Yield } & $0.085^{* * *}$ & $0.194^{* * *}$ & 0.027 & $0.108^{* * *}$ \\
\hline & $(2.79)$ & $(4.96)$ & $(0.86)$ & (2.92) \\
\hline \multirow[t]{2}{*}{ Intercept } & $16.72^{* * *}$ & $34.059^{* * *}$ & 5.609 & $18.094^{* *}$ \\
\hline & (2.83) & (4.52) & $(0.90)$ & $(2.51)$ \\
\hline $\mathbf{N}$ & 312 & 312 & 282 & 282 \\
\hline Adj. $R^{2}$ & 0.042 & 0.121 & -0.016 & 0.049 \\
\hline
\end{tabular}

Note: The table reports the results of the predictive regressions of U.S. (USmom) and global (Gmom) winner and loser portfolio returns against risk aversion, after controlling for various predictors. Winner (loser) portfolios refer to the highest (lowest) decile portfolios sorted on their past returns. MKT is the lagged 36-month stock market return, and VOL is the lagged 12-month stock market volatility. ${ }^{* * * * * *}$, and ${ }^{*}$ indicate statistical significance at $1 \%, 5 \%$, and $10 \%$, respectively.

We observe that risk aversion positively predicts the subsequent performance of past losers, even after controlling for the other traditional predictors employed in the literature. While dividend yield seems to be a robust predictor for both U.S. and global loser portfolios, risk aversion is also found to capture positive predictive power over the subsequent performance of loser portfolios for the U.S. and global markets. Interestingly, in the case of the U.S., risk 
aversion comes out as a significant predictor for both the winner and loser portfolios; however, considering that the predictive coefficient is larger for loser portfolios (2.405) compared to winner portfolios (1.113), we conclude that the negative predictive power of risk aversion over momentum returns is primarily driven by its positive predictive power over the subsequent performance of loser stocks.

Finally, we examine whether the predictive power of risk aversion over momentum returns has any economic implications. For this purpose, given the finding that high-risk aversion predicts lower momentum returns, we propose a conditional (based on risk-aversion) momentum strategy that adopts a contrarian strategy (i.e. buy loser and sell winner stocks) at the beginning of month ( $t$ ), if risk aversion is high over the preceding 3 month period; otherwise, adopt the conventional momentum strategy. In this strategy, the decision is made at the beginning of month $t$ given the level of risk aversion in the previous period and the switch to the contrarian strategy when the market is in high-risk aversion state is based on the negative predictive relationship between risk aversion and momentum returns so that high-risk aversion predicts lower momentum returns.

\section{Table 5: The out-of-sample performance of the risk aversion-based momentum} strategy

\begin{tabular}{cc|cc}
\hline \multicolumn{2}{c|}{ U.S. } & \multicolumn{2}{c}{ Global (ex U.S.) } \\
\hline $\begin{array}{c}\text { Conditional } \\
\text { Momentum }\end{array}$ & $\begin{array}{c}\text { Conventional } \\
\text { Momentum }\end{array}$ & $\begin{array}{c}\text { Conditional } \\
\text { Momentum }\end{array}$ & $\begin{array}{c}\text { Conventional } \\
\text { Momentum }\end{array}$ \\
\hline
\end{tabular}

Panel A: Risk aversion state based on the past 3-month average

\begin{tabular}{lcc|cc}
\hline Mean & $1.016 \%$ & $0.476 \%$ & $0.718 \%$ & $0.708 \%$ \\
Std. Deviation & $4.408 \%$ & $4.899 \%$ & $4.279 \%$ & $3.626 \%$ \\
Information Ratio & 0.231 & 0.097 & 0.168 & 0.195 \\
\hline
\end{tabular}

Panel B: Risk aversion state based on the past 6-month average

\begin{tabular}{lcc|cc}
\hline Mean & $1.155 \%$ & $0.476 \%$ & $1.03 \%$ & $0.708 \%$ \\
Std. Deviation & $4.189 \%$ & $4.899 \%$ & $3.948 \%$ & $3.626 \%$ \\
Information Ratio & 0.276 & 0.097 & 0.261 & 0.195 \\
\hline
\end{tabular}

Note: The table reports the average monthly out-of-sample payoffs for the conditional (based on risk-aversion) momentum strategy and the conventional momentum strategy. The conventional momentum strategy buys (sells) past winner (loser) stocks based on past performance over months ( $t-2, t-12)$. The conditional (based on risk-aversion) momentum strategy adopts a contrarian strategy (i.e. buy loser and sell winner stocks) at the beginning of month ( $t$ ), if risk aversion is high over the preceding 3-month period; otherwise, adopt the conventional momentum strategy. Mean and Std. Dev. are the mean and the standard deviation of monthly returns for the corresponding investment strategy. Information ratio is computed as the ratio of mean return to standard deviation. Panels A and B report the findings when the risk aversion state is defined based on the average risk aversion for the past 3 and 6 months, respectively, compared to the average 12-month risk aversion.

Table 5 reports the average monthly out-of-sample payoffs for the conventional and the conditional momentum strategy based on risk-aversion. For robustness checks, Panels A and B in the table report the findings when the risk aversion state is defined based on the average risk aversion for the past 3 and 6 months, respectively, compared to the average 12-month risk 
aversion. We observe that the conditional momentum strategy offers a more favourable riskadjusted return (implied by the information ratio) compared to the conventional momentum strategy, suggesting that conditioning momentum trades based on the risk aversion state can help improve the risk/return profile of conventional momentum trades. Accordingly, one can conclude that the predictive power of time-varying risk aversion over momentum returns has significant economic implications with the potential to improve the profitability of the conventional momentum strategy.

\section{Conclusion}

This paper examines the predictive power of time-varying risk aversion over the profitability of momentum strategies for the U.S. and globally. We show that risk aversion is a robust predictor of momentum returns even after controlling for various well-established stock market predictors and the market state. Further analysis shows that risk aversion absorbs the predictive power of market volatility and negatively predicts subsequent momentum returns. Examining possible asymmetries in predictability patterns, we further find that the negative predictive power of risk aversion over momentum returns is primarily driven by its positive predictive power over the subsequent performance of past loser stocks. Finally, our findings indicate that the predictive relationship between time-varying risk aversion and momentum returns can be exploited in a conditional strategy based on the level of risk aversion, implied by improved risk/return tradeoffs offered by the conditional momentum strategy compared to the conventional momentum strategy. For future research, it would be interesting to examine investor holding data and explore whether changes in risk aversion affect buy and sell trades for past loser and winner stocks in an asymmetric manner during high and low-risk aversion states as noted by Antoniou et al. (2013).

\section{References}

Ang, A., and Bekaert, G. 2002. International asset allocation with regime shifts. Review of Financial Studies, 15, 1137-1187.

Antoniou, C., Doukas, J. A., and Subrahmanyam, A. 2013. Cognitive Dissonance, Sentiment, and Momentum. The Journal of Financial and Quantitative Analysis 48 (1), 245-275.

Asness, C. S., 1994. Variables that explain stock returns. Ph.D. Dissertation, University of Chicago.

Avramov, D. and Chordia, T., 2006. Asset pricing models and financial market anomalies. Review of Financial Studies 19, 1001-1040.

Baker, M., and Wurgler, J. 2006. Investor sentiment and the cross-section of stock returns. The Journal of Finance 61, 1645-1680

Baker, M., and Wurgler, J. 2007. Investor sentiment in the stock market. Journal of Economic Perspectives 21, 129-152.

Bams, D., Honarvar, I., and Lehnert, T. 2017. Risk aversion, sentiment and the cross-section of stock returns. Working paper (June 2017). University of Maastricht.

Bekaert, G., Hodrick, R., and Zhang, X. 2009. International Stock Return Comovements, Journal of Finance $64,2591-2626$. 
Bekaert, G., Engstrom, E. C., and XU, N. R. 2017. The Time Variation in Risk Appetite and Uncertainty. WORKING PAPER.

Blasco, N., Corredor, P., and Ferrervela. S. 2012.Market sentiment: A key factor of investors' imitative behaviour. Accounting and Finance 52 (3), 663-689.

Brown, G.W., and Cliff, M.T. 2005. Investor Sentiment and Asset Valuation*. The Journal of Business 78, 405-440

Brown, N., Wei, K. and Wermers, R. 2014. Analyst recommendations, mutual fund herding, and overreaction in stock prices. Management Science 60 (1), 1-20.

Chiang, M.-T., and Lin, M.-C. 2019. Market sentiment and herding in analysts' stock recommendations. The North American Journal of Economics and Finance 48, 48-64.

Daniel, K., Hirshleifer, D., and Subrahmanyam, A. 1998. Investor psychology and security market under- and overreaction. Journal of Finance 53, 1839-1886.

Dasgupta, A., Prat, A., and Verardo, M. 2011. The price impact of institutional herding, Review of Financial Studies 24 (3), 892-925.

Demirer, R., Omay, T., Yuksel, A., and Yuksel, A. 2018. Global Risk Aversion and Emerging Market Return Comovements. Economics Letters 173,118-121.

Demirer, R., and Zhang, H. 2019a. Industry herding and the profitability of momentum strategies during market crises. Journal of Behavioral Finance 20 (2), 195-212.

Demirer, R., and Zhang, H. 2019b. Do firm characteristics matter in explaining the herding effect on returns? Review of Financial Economics 37 (2), 256-271.

Frazzini, A., and Lamont, A. O. 2008. Dumb money: Mutual fund flows and the cross section of stock returns. Journal of Financial Economics, 88, 299-322.

Goyal, A. , and Welch, I. 2008. A comprehensive look at the empirical performance of equity premium prediction. Rev. Financ. Stud. 21, 1455-1508 .

Guiso, L., Sapienza, P., and Zingales, L. 2018. Time varying risk aversion. Journal of Financial Economics 128, 403-421.

Hong, H., and Stein, J.C. 1999. A unified theory of underreaction, momentum trading and overreaction in asset markets. Journal of Finance 54, 2143-2184.

Hong, H., Lim, T., and Stein, J.C. 2000. Bad News Travels Slowly: Size, Analyst Coverage, and the Profitability of Momentum Strategies. Journal of Finance 55, 265-295.

Huang, D., Jiang, F., Tu, J., Zhou, G. 2015. Investor Sentiment Aligned: A Powerful Predictor of Stock Returns. Review of Financial Studies 28 (3), 791-837.

Hvidkjaer, S. 2006. A trade-based analysis of momentum. Review of Financial Studies 19, 457491.

Jegadeesh, N., and Titman, S. 1993. Returns to buying winners and selling losers: Implications for stock market efficiency, Journal of Finance 48, 65-91.

Jegadeesh, N., and Titman, S. 2001. Profitability of momentum strategies: an evaluation of alternative explanations. Journal of Finance 56, 699-720.

Lemmon, M., and Ni, S. X. 2011 . The effects of investor sentiment on speculative trading and prices of stock and index options. SSRN working paper.

Liu, L. X., and Zhang, L. 2008. Momentum profits, factor pricing, and macroeconomic risk, Review of Financial Studies 21, 2417-2448.

Miranda-Agrippino, S., and Rey, H. 2015. World asset markets and the global financial cycle. NBER Working Paper: 21722 (Revised Feb. 2018). 
Nofsinger, J., and Sias, R. 1999. Herding and feedback trading by institutional and individual investors. Journal of Finance 54, 2263-2295.

Rey, H. 2018. Dilemma not trilemma: The global financial cycle and monetary policy independence. NBER Working Paper: 21162 (Feb. 2018).

Sadka, R. 2006. Momentum and post-earnings-announcement drift anomalies: the role of liquidity risk. Journal of Financial Economics 80, 309-349.

Sias, R. 2004. Institutional herding. Review of Financial Studies 17 (1), 165-206.

Singh, V. 2013. Did Institutions Herd During the Internet Bubble? Review of Quantitative Finance and Accounting 41, 513-534.

Wang, K. Q. and XU, J. 2015. Market volatility and momentum. Journal of Empirical Finance 30, 79-91.

XU, N. R. 2017. Global Risk Aversion and International Return Comovements. Working paper (Dec. 11, 2017). 